\title{
Utilização de três métodos imuno-histoquímicos na detecção de aspergilose e zigomicose em animais ${ }^{1}$
}

\author{
Glauco J.N. Galiza², Camila Tochetto², Fábio B. Rosa², Welden Panziera², Taiara M. \\ da Silva ${ }^{3}$, Rafaela A. Caprioli ${ }^{3}$ e Glaucia D. Kommers ${ }^{4 *}$
}

\begin{abstract}
Galiza G.J.N., Tochetto C., Rosa F.B., Panziera W., Silva T.M., Caprioli R.A. \& Kommers G.D. 2014. [Usage of three immunohistochemical methods in the detection of aspergillosis and zygomycosis in animals.] Utilização de três métodos imuno-histoquímicos na detecção de aspergilose e zigomicose em animais. Pesquisa Veterinária Brasileira 34(7):637-642. Laboratório de Patologia Veterinária, Departamento de Patologia, Universidade Federal de Santa Maria, Camobi, Santa Maria, RS 97105-900, Brazil. E-mail: glaukommers@yahoo.com

Aiming to optimize the usage of the immunohistochemical technique (IHC) in the detection of Aspergillus spp. and zygomycetes (members of the Mucoraceae family), two fungal-specific monoclonal antibodies were used in tissue fragments (formalin-fixed paraffin-embedded), previously diagnosed by histomorphology as aspergillosis and zygomycosis. Tissues were submitted to three different detection systems (two biotinilated and one non biotinilated). Both antibodies showed high specificity and sensitivity in the examined tissues. No cross-reactions were observed between the antibodies used and the agents evaluated (including cases of aspergillosis, zygomycosis, candidiasis and pythiosis). However, nonspecific reactions in hyphae were observed in some cases, but were eliminated by mean of one of the detection systems used. In the aspergillosis cases, with the streptavidin-biotin-alkaline phosphatase method, nonspecific reactions were not observed. In the zygomycosis cases, nonspecific reactions did not occur using a polymer (nonbiotinilated). The IHC technique showed to be a useful tool detecting and confirming aspergillosis and zygomycosis in this retrospective study.
\end{abstract}

INDEX TERMS: Aspergillosis, zygomycosis, immunohistochemistry, mycoses, cross-reactions, nonspecific reactions.

RESUMO.- Visando a otimização do uso da técnica de imuno-histoquímica (IHQ) na deteç̧ão de Aspergillus spp. e zigomicetos (membros da família Mucoraceae), utilizaram-se dois anticorpos monoclonais fungo-específicos em fragmentos de tecidos de animais (fixados em formol e embebidos em parafina) com diagnóstico histomorfológico prévio de aspergilose e zigomicose, os quais foram submetidos a

\footnotetext{
${ }^{1}$ Recebido em 7 de abril de 2014.

Aceito para publicação em 26 de maio de 2014.

Parte da Tese de Doutorado do primeiro autor.

${ }^{2}$ Programa de Pós-Graduação em Medicina Veterinária, área de concentração em Patologia e Patologia Clínica Veterinária, Centro de Ciências Rurais (CCR), Universidade Federal de Santa Maria (UFSM), Av. Roraima 1000, Camobi, Santa Maria, RS 97105-900, Brasil.

${ }^{3}$ Curso de Medicina Veterinária, CCR-UFSM, Santa Maria, RS.

${ }^{4}$ Laboratório de Patologia Veterinária, Departamento de Patologia, Centro de Ciências da Saúde, UFSM, Santa Maria, RS. *Autor para correspondência: glaukommers@yahoo.com
}

três sistemas de detecção diferentes (dois biotinilados e um não biotinilado). Os dois anticorpos apresentaram alta especificidade e sensibilidade nos tecidos examinados. Não ocorreram reações cruzadas entre os anticorpos utilizados e os agentes etiológicos avaliados (incluindo casos de aspergilose, zigomicose, candidíase e pitiose). No entanto, reações inespecíficas foram observadas nas hifas em alguns casos, as quais puderam ser eliminadas através de um dos métodos de detecção utilizados. Para a aspergilose, o método da estreptavidina-biotina-fosfatase alcalina não apresentou reações inespecíficas nas hifas. Enquanto que nos casos de zigomicoses, as reações inespecíficas não ocorreram no método por polímero (não biotinilado). A técnica de IHQ mostrou-se uma ferramenta muito útil na detecção e confirmação dos casos de aspergilose e zigomicose neste estudo retrospectivo.

TERMOS DE INDEXAÇÃO: Aspergilose, zigomicose, imuno-histoquímica, micoses, reações cruzadas, reações inespecíficas. 


\section{INTRODUÇÃO}

$\mathrm{Na}$ rotina em patologia veterinária, frequentemente agentes fúngicos são detectados somente durante o exame histopatológico, quando as amostras já estão fixadas em formol e não há possibilidade de envio para exames micológicos de cultura e identificação do agente específico (Jensen et al. 1996a).

A técnica de imuno-histoquímica (IHQ) é frequentemente utilizada para o estudo de doenças infecciosas e neoplásicas em animais (Ramos-Vara \& Beissenherz 2000), sendo uma ferramenta auxiliar no diagnóstico dessas condições devido a sua alta especificidade e sensibilidade (Eyzaguirre \& Haque 2008, Ramos-Vara et al. 2008, Ramos-Vara \& Miller 2014). Também tem sido utilizada para detectar e identificar vários elementos fúngicos em tecidos fixados em formol, promovendo uma identificação específica do agente etiológico (Jensen et al. 1996b, Verweij et al. 1996, Eyzaguirre \& Haque 2008).

Para que haja uma otimização do uso da técnica de IHQ na detecção de micoses, na medida em que novos anticorpos fungo-específicos vão sendo disponibilizados, tornam-se necessários estudos onde várias amostras fixadas em formol e embebidas em parafina sejam utilizadas, vários métodos imuno-histoquímicos sejam testados e onde haja uma associação compatível entre os achados da IHQ e a histopatologia. Alguns desses estudos têm sido publicados (Jensen et al. 1994, Rocha et al. 1998, Choi et al. 2004, Schuetz \& Cohen 2009) e são de grande valor no aprimoramento do uso da IHQ para detecção e identificação de fungos na rotina em patologia veterinária.

Este estudo teve como objetivo utilizar três diferentes métodos imuno-histoquímicos em casos de aspergilose e zigomicose, previamente diagnosticados no Laboratório de Patologia Veterinária (LPV) da Universidade Federal de Santa Maria (UFSM), visando caracterizar as melhores condições imuno-histoquímicas para a detecção específica dos agentes etiológicos nos tecidos testados.

\section{MATERIAL E MÉTODOS}

Casos de aspergilose (oito em aves e um em bovino) e zigomicose (cinco em bovinos, um em cão, um em suíno e um em ovino) foram selecionados dos arquivos do LPV-UFSM, os quais haviam sido previamente diagnosticados de acordo com a histomorfologia do agente, com as lesões macroscópicas e microscópicas e com a cultura micológica (esta última disponível em três casos de aspergilose em aves). Foi então realizada a técnica de IHQ em amostras desses casos para detecção de Aspergillus spp. e Rhizopus arrhizus (ou outros zigomicetos membros da família Mucoraceae, tais como Absidia corymbifera e Rhizomucor pusillus) utilizando-se os anticorpos primários monoclonais (produzidos em camundongo) anti-Aspergillus spp. (Clone WF-AF-1, AbD Serotec) e anti-Rhizopus arrhizus (Clone WSSA-RA-1, AbD Serotec), respectivamente. As seções de tecidos foram submetidas ao protocolo de IHQ descrito a seguir e de acordo com as três variações nos sistemas de detecção descritas no Quadro 1. Quando necessário, foi realizado o bloqueio da peroxidase endógena com peróxido de hidrogênio a 3\% (2x de 10 minutos). Em todos os protocolos, o bloqueio das reações inespecíficas foi realizado com caseína (leite em pó desnatado) a $5 \%$ por 30 minutos em temperatura ambiente. Como controle negativo de cada caso utilizou-se uma secção do tecido analisado incubado apenas com o diluente do anticorpo (PBST), possibilitando assim a avaliação de possíveis reações inespecíficas nas hifas. A avaliação da especificidade (ocorrência ou não de reações cruzadas) dos anticorpos primários foi realizada através da IHQ para cada anticorpo com amostras de tecidos de casos selecionados de zigomicose (quatro casos), aspergilose (três casos), candidíase (dois casos) e pitiose (um caso).

\section{RESULTADOS}

Imunomarcação positiva, utilizando-se os respectivos anticorpos, foi observada em todos os casos de zigomicose e aspergilose analisados através dos três métodos imuno-histoquímicos utilizados.

Nos casos de zigomicose, os três métodos imuno-histoquímicos foram eficientes e geralmente demonstraram um padrão de imunomarcação no citoplasma das hifas. Nos métodos da estreptavidina-biotina-peroxidase e no sistema por polímero a imunomarcação foi forte em todos os casos (Fig.1A e E). 0 método da estreptavidina-biotina-fosfatase alcalina apresentou imunomarcação leve ou forte (Fig.1C). Nos protocolos utilizando-se os sistemas estreptavidina-biotina-peroxidase ou fosfatase alcalina observou-se reação inespecífica, de intensidade variada, nas hifas nos controles negativos, as quais ocorreram no citoplasma e na parede de algumas hifas (Fig.1B e D). Dos oito casos avaliados no sistema estreptavidina-biotina-peroxi-

Quadro 1. Descrição dos protocolos de imuno-histoquímica executados com os anticorpos anti-Rhizopus arrhizus e anti-Aspergillus spp.

\begin{tabular}{|c|c|c|c|c|c|}
\hline$A c^{\mathrm{a}}$ & $\begin{array}{c}\text { Recuperação } \\
\text { antigênica }\end{array}$ & Diluiçãob $^{\text {b }}$ & $\begin{array}{l}\text { Incubação (tempo/ } \\
\text { temperatura) }\end{array}$ & $\begin{array}{l}\text { Ac secundário/ } \\
\text { amplificador }\end{array}$ & Cromógeno \\
\hline $\begin{array}{l}\text { Anti-Rhizopus } \\
\text { arrhizus }\end{array}$ & $\begin{array}{l}\text { Tris-EDTA } \\
\text { (pH 9,0) }\end{array}$ & $1: 50$ & $1 \mathrm{~h} / 37^{\circ} \mathrm{C}$ & $\begin{array}{l}\text { LSAB+System HRP } \\
\text { EasyLink One }{ }^{\mathrm{e}} \\
\text { LSAB+System AP }^{\mathrm{f}}\end{array}$ & $\begin{array}{l}\mathrm{DAB}^{\mathrm{d} *} \\
\mathrm{DAB}^{*} \\
\mathrm{LPR}^{\mathrm{g} * *}\end{array}$ \\
\hline $\begin{array}{l}\text { Anti-Aspergillus } \\
\text { spp. }\end{array}$ & $\begin{array}{l}\text { Tris-EDTA } \\
(\mathrm{pH} \mathrm{9,0)}\end{array}$ & $1: 300$ & $1 \mathrm{~h} / 37^{\circ} \mathrm{C}$ & $\begin{array}{c}\text { LSAB+System HRP } \\
\text { EasyLink One } \\
\text { LSAB+System AP }\end{array}$ & $\begin{array}{l}\mathrm{DAB}^{*} \\
\mathrm{DAB}^{*} \\
\mathrm{LPR}^{* *}\end{array}$ \\
\hline
\end{tabular}

\footnotetext{
${ }^{\mathrm{a}}$ Ac $=$ anticorpo, ${ }^{\mathrm{b}}$ Anticorpo diluído em PBST (tampão salina fosfato com Tween ${ }^{\circledR} 20$-Sigma), ${ }^{\mathrm{c}} \mathrm{LSAB}+$ System HRP = anticorpo secundário biotinilado e o complexo estreptavidina-biotina-peroxidase (Dako), ${ }^{\mathrm{d}} \mathrm{DAB}=$ Liquid DAB (3,3'diaminobenzidine) + Substrate-Choromogen System (Dako), ${ }^{\mathrm{e}}$ EasyLink One $=$ Amplificador+Polímero HRP $($ Easypath $),{ }^{\mathrm{f}} \mathrm{LSAB}+$ System AP $=$ anticorpo secundário biotinilado e o complexo estreptavidina-biotina-fosfatase alcalina (Dako), ${ }^{\mathrm{g}} \mathrm{LPR}=\mathrm{Li}$ quid Permanent Red (Dako). ${ }^{*}$ Contracorados com hematoxilina de Harris. ${ }^{* *}$ Contracorados com hematoxilina de Mayer.
} 


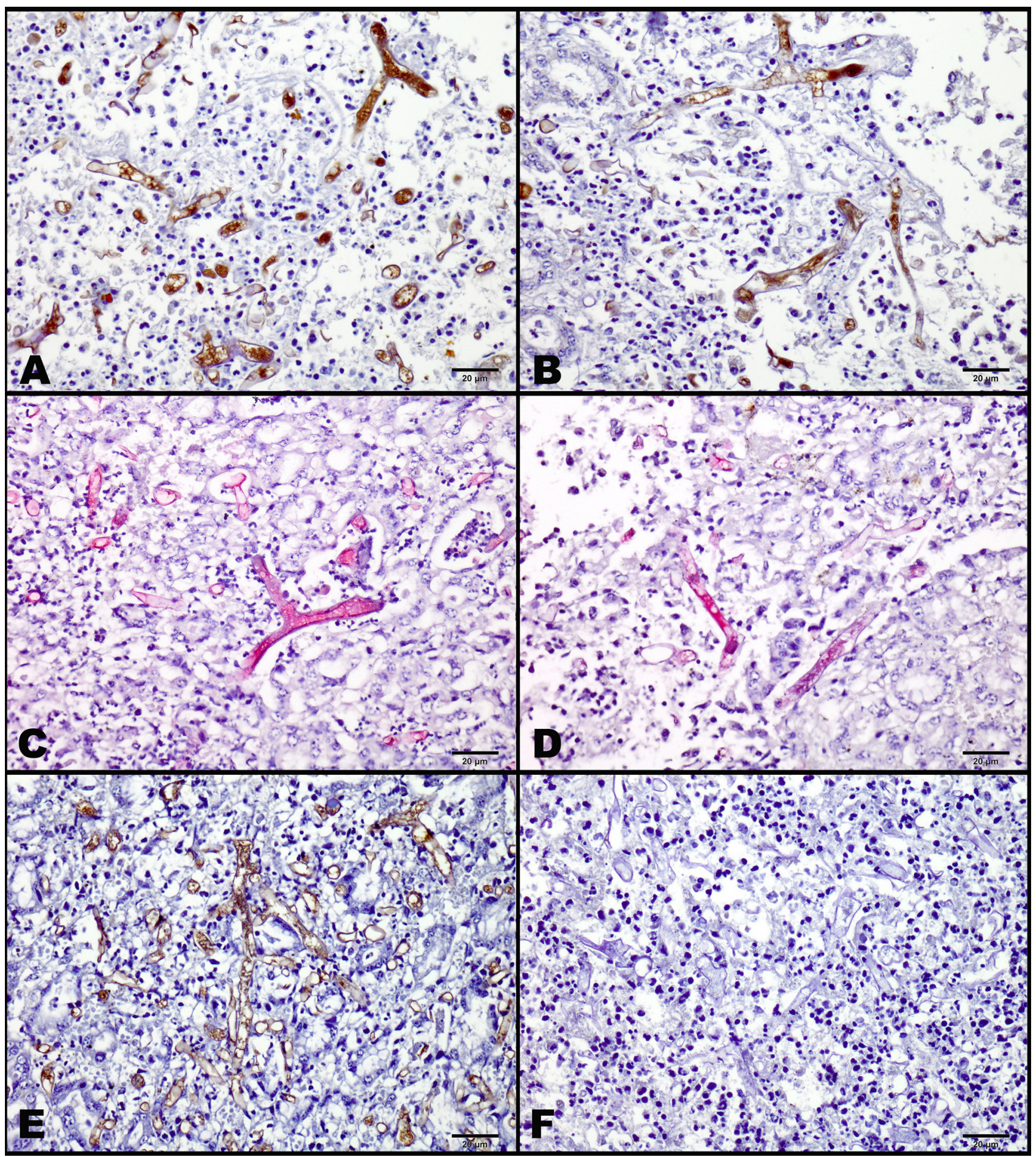

Fig.1. Imuno-histoquímica para zigomicose. (A) Hifas fortemente imunomarcadas no citoplasma. Método da estreptavidina-biotina-peroxidase. (B) Reação inespecífica no citoplasma das hifas no controle negativo. Mesmo método da Figura 1A. (C) Hifas fortemente imunomarcadas no citoplasma. Método da estreptavidina-biotina-fosfatase alcalina. (D) Reação inespecífica no citoplasma das hifas no controle negativo. Mesmo método da Figura 1C. (E) Hifas fortemente imunomarcadas no citoplasma. Método por polímero. (F) Hifas sem reação inespecífica no controle negativo. Mesmo método da Figura 1E. Barra $=20 \mu \mathrm{m}$.

dase, seis apresentaram reações inespecíficas nas hifas. No método da estreptavidina-biotina-fosfatase alcalina, cinco casos apresentaram reações inespecíficas nas hifas. No método utilizando-se um polímero não se observaram reações inespecíficas nas hifas nos controles negativos (Fig.1F).

Nos casos de aspergilose, os três métodos apresentaram imunomarcação eficiente, principalmente na parede e no citoplasma das hifas, variando de moderada a forte. Nos nove casos analisados através do método da estreptavidina-biotina-peroxidase, cinco apresentaram imunomarcação forte e quatro moderada (Fig.2A). Em dois casos com imunomarcação forte também se observaram reações inespecíficas, 
de intensidade variada, na parede e no citoplasma das hifas nos controles negativos (Fig.2B). Semelhantemente ao descrito no sistema estreptavidina-biotina-peroxidase, os casos analisados com polímero apresentaram imunomarcação forte (cinco) e moderada (quatro) (Fig.2E). Em dois casos com imunomarcação forte observaram-se também reações inespecíficas, de intensidade variada, no citoplasma das hifas nos controles negativos (Fig.2F). As reações inespecíficas ocorreram nos mesmos dois casos testados pelos sistemas de polímero e da estreptavidina-biotina-

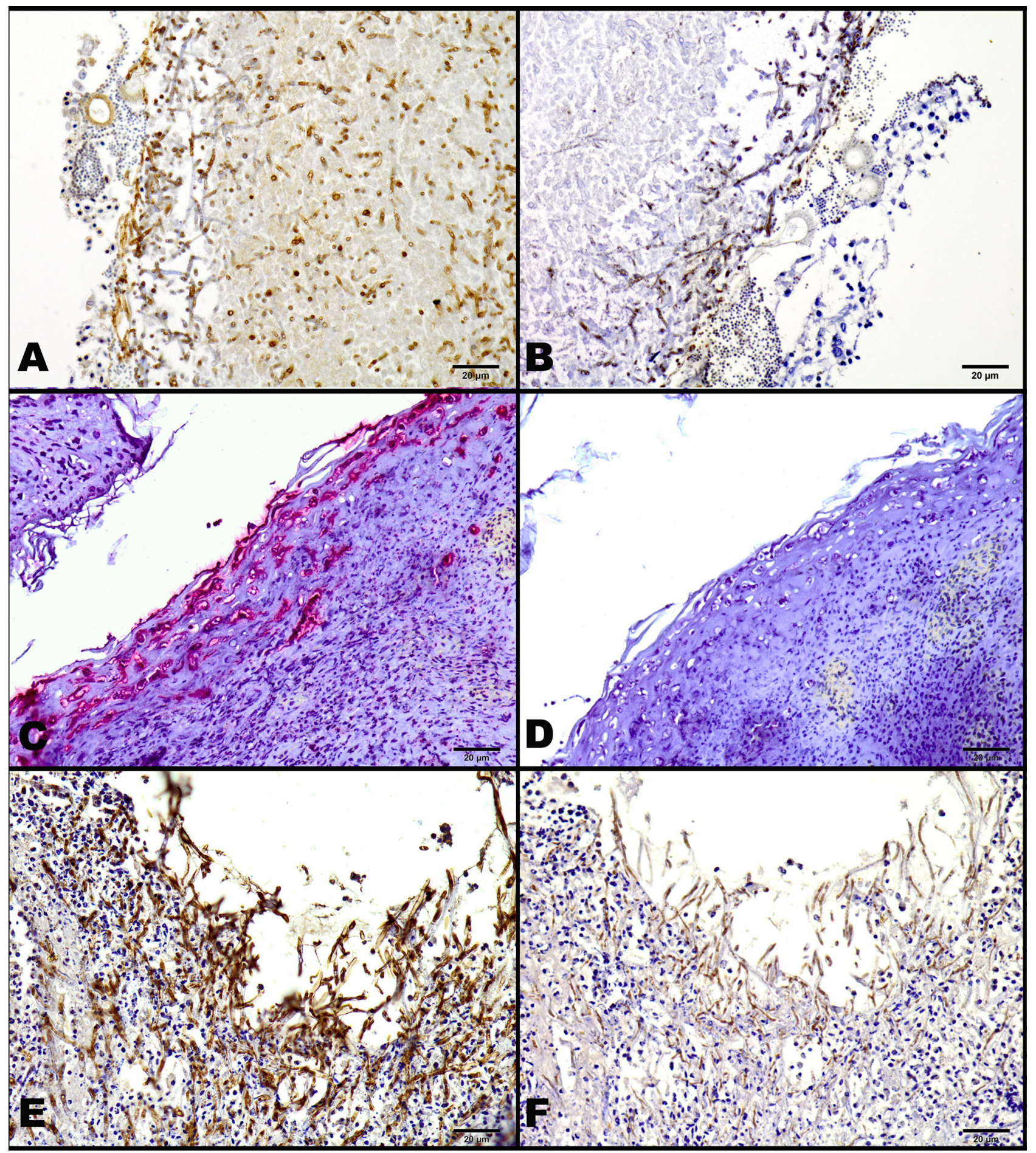

Fig.2. Imuno-histoquímica para aspergilose. (A) Hifas fortemente imunomarcadas na parede e no citoplasma. Método da estreptavidina-biotina-peroxidase. (B) Reação inespecífica no citoplasma e nas paredes das hifas no controle negativo. Mesmo método da Figura 2A. (C) Hifas fortemente imunomarcadas na parede e no citoplasma. Método estreptavidina-biotina-fosfatase alcalina. (D). Hifas sem reação inespecífica no controle negativo. Mesmo método da Figura 2C. (E) Hifas fortemente imunomarcadas na parede e no citoplasma. Método por polímero. (F) Reação inespecífica no citoplasma e na parede das hifas no controle negativo. Mesmo método da Figura 2E. Barra $=20 \mu \mathrm{m}$. 
-peroxidase. No protocolo utilizando-se o sistema estreptavidina-biotina-fosfatase alcalina a imunomarcação foi forte em todos os casos, no entanto não ocorreram reações inespecíficas nas hifas dos controles negativos (Fig.2C,D). Nos casos de aspergilose em que foi possível a visualização de conidióforos nos tecidos analisados, não se evidenciou imunomarcação dessas estruturas através de nenhum dos métodos utilizados.

Em todos os casos de zigomicose e aspergilose avaliados pelos três métodos observam-se raras hifas sem reação positiva (citoplasma pálido e paredes basofílicas ou imagens negativas) em meio a hifas imunomarcadas. Frequentemente essas hifas não imunomarcadas estavam em áreas de necrose ou no centro dos granulomas.

\section{DISCUSSÃO}

Os anticorpos monoclonais anti-Aspergillus spp. e anti-Rhizopus arrhizus demonstraram forte imunomarcação nos casos testados (tecidos fixados em formol e embebidos em parafina), os quais haviam sido previamente diagnosticados como aspergilose ou zigomicose baseado nas respectivas características histomorfológicas dos fungos e na localização e no tipo de reação tecidual observada em cada caso (Guarner \& Brandt 2011).

Os sistemas de detecção (biotinilados e não biotinilados) são muito importantes para maximizar a sensibilidade dos testes de IHQ e para otimizar a visualização da reação imune com o menor número de etapas e no menor tempo possível (Ramos-Vara \& Miller 2014). Para os casos de zigomicoses, o método imuno-histoquímico utilizando o polímero foi o mais eficiente, demonstrando alta sensibilidade e especificidade, enquanto que para os casos de aspergilose, o método da estreptavidina-biotina-fosfatase alcalina apresentou elevada sensibilidade e especificidade nos casos testados neste estudo. A localização da imunomarcação nas hifas observada nos casos de zigomicose (ocorrendo principalmente no citoplasma) e aspergilose (na parede, nos septos e no citoplasma) pode estar associada ao tipo de antígeno específico de cada anticorpo. De acordo com alguns autores (Jensen et al. 1996b, Choi et al. 2004), anticorpos contra antígenos somáticos solúveis em água (water-soluble somatic antigens - WSSA) geralmente reagem com estruturas presentes no citoplasma (componentes não estruturais), enquanto anticorpos contra antígenos presentes nas frações da parede (wall fraction - WF) reagem com componentes estruturais presentes principalmente na parede, septos e citoplasma. A diferenciação na localização da imunomarcação auxilia na interpretação dos resultados da técnica de imuno-histoquímica para fungos, bem como para outros agentes (Ramos-Vara et al. 2008).

A ausência de imunomarcação nos conidióforos, observada nos casos de aspergilose, pode estar associada à variação na capacidade de imunomarcação dos elementos fúngicos devido às diferenças existentes na composição antigênica nas diferentes fases de desenvolvimentos dos fungos (Fukuzawa et al. 1995).

A identificação de reações inespecíficas neste estudo só foi possível devido à utilização de controles negativos (seções dos mesmos casos testados) com a presença do agente etiológico. A utilização de controles negativos em testes de IHQ é de extrema importância para avaliação da sensibilidade do anticorpo primário versus a ocorrência de reações inespecíficas (Ramos-Vara et al. 2008).

A ocorrência de reações inespecíficas observadas nos controles negativos (incubados somente com o diluente, sem a utilização de anticorpo primário) nos casos de zigomicose avaliados através dos métodos da estreptavidina-biotina-peroxidase ou fosfatase alcalina, pode estar associada à presença endógena de biotina, avidina, estreptavidina ou proteínas com características semelhantes às descritas anteriormente no citoplasma das hifas. Estudos têm demonstrado a presença endógena de biotina, avidina, estreptavidina e proteínas semelhantes à avidina em diversas espécies de fungos (Shchelokova \& Vorob'eva 1982, Matsuhisa et al. 1993, Hall \& Dietrich 2007, Takakura et al. 2009). A presença de biotina endógena nas hifas de alguns casos poderia ter causado uma ligação inespecífica com a estreptavidina do sistema de detecção biotinilado. Vale salientar que não foram utilizados bloqueadores comerciais específicos para avidina ou biotina endógenas nos casos aqui avaliados. Um aspecto que sugere a associação das reações inespecíficas com o sistema biotinilado vistas nos casos de zigomicose testados é a ausência dessas reações em casos em que se utilizou um polímero (sistema não biotinilado).

No entanto, as reações inespecíficas observadas nos dois casos de aspergilose utilizando-se os métodos (estreptavidina-biotina-peroxidase ou polímero com peroxidase), em que o cromógeno DAB (diaminobenzidina) era o indicado e aplicado, poderiam estar associadas à presença de peroxidase endógena, descrita em algumas espécies de fungos (incluindo Aspergillus sp.) sob determinadas condições (Aifa et al. 1999, Conesa et al. 2000). Isto é corroborado pela ausência de reações inespecíficas quando se utilizou o sistema estreptavidina-biotina-fosfatase alcalina e outro tipo de cromógeno indicado para esse método. A reação inespecífica observada nos controles negativos teria ocorrido diretamente entre a peroxidase endógena do fungo e o substrato-cromógeno (peróxido de hidrogênio-diaminobenzidina) nesses casos. 0 bloqueio da peroxidase endógena realizado no protocolo não teria sido suficiente nesses casos.

Não foram observadas reações cruzadas entre os anticorpos anti-Rhizopus arrhizus e anti-Aspergillus spp. nos casos de aspergilose, zigomicose, candidíase e pitiose aqui testados, demonstrando uma alta especificidade desses anticorpos. Entretanto, diversos estudos realizados com determinados anticorpos anti-antígenos fungo-específicos têm demonstrado reações cruzadas na IHQ (Reed et al. 1993, Fukuzawa et al. 1995, Verweij et al. 1996, Schuetz \& Cohen 2009). Nesses casos, as reações cruzadas podem estar associadas às semelhanças antigênicas entre alguns fungos (Reed et al. 1993, Fukuzawa et al. 1995, Schuetz \& Cohen 2009). Na medida em que novos anticorpos (livres de reações cruzadas) são desenvolvidos e testados através da IHQ (Marcilla et al. 1999), esta técnica vai se apresentando como uma alternativa de diagnóstico específica e eficiente diante de testes mais onerosos e que não combinam a morfologia com a detecção do fungo específico (Guarner \& Brandt 2011). 
A ausência de imunomarcação, ocasionalmente vista em algumas hifas em áreas de necrose ou de intensa reação inflamatória, poderia estar associada à perda da antigenicidade nos epitopos específicos detectados pelos anticorpos monoclonais utilizados devido à ação de enzimas proteolíticas liberadas de células necróticas. A diminuição ou perda da imuno-reatividade de alguns antígenos também pode estar associada à ocorrência de ligações cruzadas durante o período de fixação, que alteram as estruturas das proteínas, devido a fatores relacionados como a temperatura e o tempo de fixação (Ramos-Vara \& Beissenherz 2000).

\section{CONCLUSÕES}

Todos os casos previamente diagnosticados como aspergilose ou zigomicose foram confirmados pela IHQ neste estudo.

A aplicação de três diferentes métodos imuno-histoquímicos (dois biotinilados e um não biotinilado) disponíveis em nosso laboratório mostrou diferenças entre os métodos quanto à intensidade da imunomarcação e quanto à ocorrência de reações inespecíficas nas hifas dos agentes testados nos controles negativos.

Para a aspergilose, o método da estreptavidina-biotina-fosfatase alcalina não apresentou reações inespecíficas nas hifas.

Nos casos de zigomicoses, as reações inespecíficas não ocorreram no método por polímero.

Isso demonstra mais uma vez a necessidade da busca do melhor protocolo de IHQ sempre que um novo anticorpo é introduzido na rotina laboratorial.

Agradecimentos.- G.J.N. Galiza e C. Tochetto (doutorado), W. Panziera (mestrado), T.M. Silva e R.A. Caprioli (iniciação científica - PIBIC) são bolsistas do CNPq. F.B. Rosa (doutorado) é bolsista da CAPES. G.D. Kommers é bolsista de Produtividade do CNPq (PQ-2). 0 projeto é financiado pelo CNPq - Edital Universal (Proc. 474839/2012-5).

\section{REFERÊNCIAS}

Aifa M.S., Sayadi S. \& Gargouri A. 1999. Heterologous expression of lignin peroxidase of Phanerochaete chrysosporiumin Aspergillus niger. Biotechnol. Lett. 21(10):849-853.

Choi J.K., Mauger J. \& McGowan K.L. 2004. Immunohistochemical detection of Aspergillus species in pediatric tissue samples. Am. J. Clin. Pathol. 121:18-25.

Conesa A., Hondel C.A.M.J.J.V.D. \& Punt P.J. 2000. Studies on the production of fungal peroxidases in Aspergillus niger. Appl. Environ. Microbiol. 66(7):3016-3023.

Eyzaguirre E. \& Haque A.K. 2008. Application of immunohistochemistry to infections. Arch. Pathol. Lab. Med. 132(3):424-431.
Fukuzawa M., Inaba H., Hayama M., Sakaguchi N., Sano K., Ito M. \& Hotchi M. 1995. Improved detection of medically important fungi by immunoperoxidase staining with polyclonal antibodies Virchows Arch. 427:407-414.

Guarner J. \& Brandt M.E. 2011. Histopathologic diagnosis of fungal infections in the $21^{\text {st }}$ Century. Clin. Microbiol. Rev. 24(2):247-280.

Hall C. \& Dietrich F.S. 2007. The reacquisition of biotin prototrophy in Saccharomyces cerevisiae involved horizontal gene transfer, gene duplication and gene clustering. Genetics. 177(4):2293-2307.

Jensen H.E., Olsen S.N. \& Aalbaek B. 1994. Gastrointestinal aspergilosis and zygomycosis of cattle. Vet. Pathol. 31(1):28-36.

Jensen H.E., Schønheyder H.C., Hotchi M. \& Kaufman L. 1996a. Diagnosis of systemic mycoses by specific immunohistochemical tests. APMIS 104:(4)241-258.

Jensen H.E., Aalbaek B., Lind P. \& Krogh H.V. 1996b. Immunohistochemical diagnosis of systemic bovine zygomycosis by murine monoclonal antibodies. Vet. Pathol. 33(2):176-183.

Marcilla A., Monteagudo C., Mormeneo S. \& Sentandreu R. 1999. Monoclonal antibody 3H8: a useful tool in the diagnosis of candidiasis. Microbiology 145(3):695-701.

Matsuhisa A., Saito Y., Ueyama H., Yamamoto M. \& Ohono T. 1993. Binding of streptavidin to bacteria or fungi and its applications in detecting these microbes. Microbiol. Immunol. 37(10):765-772.

Ramos-Vara J.A. \& Beissenherz M.E. 2000. Optimization of immunohistochemical methods using two different antigen retrieval methods on formalin-fixed paraffin-embedded tissues: experience with 63 markers. J. Vet. Diagn. Invest. 12(4):307-311.

Ramos-Vara J.A., Kiupel M., Baszler T., Bliven L., Brodersen B., Chelack B., Czub S., Del Piero F., Dial S., Ehrhart E.J., Graham T., Manning L., Paulsen D., Valli V.E. \& West K. 2008. Suggested guidelines for immunohistochemical techniques in veterinary diagnostic laboratories. J. Vet. Diagn. Invest. 20(4):393-413.

Ramos-Vara J.A. \& Miller M.A. 2014. When tissue antigens and antibodies get along: revisiting the technical aspects of immunohistochemistry the Red, Brown, and Blue Technique. Vet. Pathol. 51(1):42-87.

Reed J.A., Hemann B.A., Alexander J.L. \& Brigati D.J. 1993. Immunomycology: rapid and specific immunocytochemical identification of fungal in formalin-fixed, paraffin-embedded material. J. Histochem. Cytochem. 41(18):1217-1221.

Rocha D.C.A., Duarte M.I.S., Pagliari C. \& Oliveira M.S. 1998. Diagnóstico imuno-histoquímico de infecções fúngicas. Revta Hosp. Clín. 53(4):184188.

Schuetz A.N. \& Cohen C. 2009. Aspergillus immunohistochemistry of culture-proven fungal tissue isolates shows high cross-reactivity. Appl. Immunohistochem. Mol. Morphol. 17(6):524-529.

Shchelokova E.V. \& Vorob'eva L.I. 1982. Biotin formation by the fungus Rhizopus delemar. Prikl. Biokhim. Mikrobiol. 18(5):630-635.

Takakura Y., Tsunashima M., Suzuki J., Usami S., Kakuta Y., Okino N., Ito M. \& Yamamoto T. 2009. Tamavidins-novel avidin-like biotin-binding proteins from the Tamogitake mushroom. FEBS J. 276(5):1383-1397.

Verweij P.E., Smedts F., Poot T., Bult P., Hoogkamp-Korstanje J.A. \& Meis J.F. 1996. Immunoperoxidase staining for identification of Aspergillus species in routinely processed tissue sections. J. Clin. Pathol. 49(10):798801. 